\title{
Determinants of vaccination coverage and adherence to the Greek national immunization program among infants aged 2-24 months at the beginning of the economic crisis (2009-2011)
}

\author{
Papaevangelou Vassiliki ${ }^{1 *}$, Koutsoumbari loanna ${ }^{2}$, Vintila Artemis ${ }^{2}, K^{\prime}$ linaki Eleni ${ }^{3}$, Zellos Aglaia ${ }^{4}$, Achilleas Attilakos ${ }^{1}$,
} Tsolia Maria ${ }^{2}$ and Kafetzis Dimitris ${ }^{2}$

\begin{abstract}
Background: Childhood immunization has significantly reduced the incidence of vaccine preventable diseases. Parental mistrust over vaccine safety has been associated with vaccine refusal creating barriers on vaccine coverage. Recently, economic crisis has imposed additional impediment.

Methods: Study aim was to evaluate vaccine coverage among infants 2-24 months old in the Athens metropolitan area at the beginning of the economic crisis (2009-2011).

Results: Overall, 1,667 infants were enrolled (mean age 13 months). Less than 5\% of parents admitted omitting or postponing vaccination secondary to their beliefs. Although vaccination coverage was acceptable for most vaccines, lower rates of immunization were found for some newer vaccines such as hepatitis A and rotavirus. Multiple regression analysis indicated that parental age, occupational, educational statuses and family size were independently associated with immunization coverage at 6 and 12 months. Interestingly, lack of insurance was not associated with missed vaccine doses.
\end{abstract}

Conclusion: Incomplete vaccination coverage was associated with socioeconomic factors. It becomes apparent, that reassessing vaccination priorities under the current economic situation may be needed.

Keywords: Vaccination, Coverage, Immigrants, Economic crisis, Socio economic factors

\section{Background}

Vaccination is one of the most cost-effective public health initiatives that prevents up to $24 \%$ of the $10-12$ million of yearly deaths of children under the age of 5 years [1]. The Expanded Program of Immunization (EPI) was initially adopted by World Health Organization (WHO) in 1974 to ensure that infants are fully immunized with the recommended childhood vaccines. Individual governments implement their own policies for vaccination programs following the international guidelines set by WHO.

\footnotetext{
* Correspondence: vpapaev@med.uoa.gr

${ }^{1}$ Third Pediatric Department, National and Kapodistrian University of Athens Medical School, University General Hospital "ATTIKON", Rimini 1, Chaidari 12462, Greece

Full list of author information is available at the end of the article
}

In Greece, the National Immunization Program (NIP) is set by the Ministry of Public Health and Social Solidarity and is provided free of charge to all residents including immigrants (Table 1) [2]. At the individual level, adherence to the NIP offers protection against infectious diseases decreasing related morbidity and mortality [3]. In addition, high vaccination coverage at population level ensures development of herd immunity against infectious diseases and protects unimmunized susceptible individuals (too young to get vaccinated, immunocompromised, etc) [4]. Recently, parental concerns about vaccine safety together with the growing complexity of the immunization schedules and the increasing number of injections has lead to a rising number of parents who elect to postpone or even refuse the administration of some vaccines for their children [5]. This attitude poses

\section{Ciomed Central}

(C) 2014 Vassiliki et al.; licensee BioMed Central Ltd. This is an Open Access article distributed under the terms of the Creative Commons Attribution License (http://creativecommons.org/licenses/by/4.0), which permits unrestricted use, distribution, and reproduction in any medium, provided the original work is properly credited. The Creative Commons Public Domain Dedication waiver (http://creativecommons.org/publicdomain/zero/1.0/) applies to the data made available in this article unless otherwise stated. 
Table 1 Greek National Immunization Programme (NIP) for children (2011)

\begin{tabular}{|c|c|c|c|c|c|c|c|c|c|c|}
\hline & Birth & 2 months & 4 months & 6 months & 12 months & 15 months & 18 months & 24 months & 4-6 years & $11-12$ years \\
\hline $\mathrm{HepB}^{1}$ & & НерB & НерB & & & & & & & \\
\hline $\mathrm{DTaP}^{2}$ & & DTaP & DTaP & DTaP & & & & & DTap & \\
\hline $\mathrm{IPV}^{3}$ & & IPV & IPV & & & & & & IPV & \\
\hline $\mathrm{Hib}^{4}$ & & $\mathrm{Hib}$ & $\mathrm{Hib}$ & $\mathrm{Hib}$ & & & & & & \\
\hline $\mathrm{MCC}^{5}$ & & MCC & MCC & & \multicolumn{6}{|c|}{ MCC } \\
\hline$P C V^{6}$ & & PCV & PCV & PCV & \multicolumn{4}{|c|}{ PCV } & & \\
\hline $\mathrm{MMR}^{7}$ & & & & & \multicolumn{2}{|c|}{ MMR } & & & MMR & \\
\hline Varicella & & & & & \multicolumn{3}{|c|}{ Var } & & Var & \\
\hline $\mathrm{HepA}^{8}$ & & & & & \multicolumn{6}{|c|}{ Hep A (2 doses) } \\
\hline $\mathrm{TB}^{9}$ & $\mathrm{BCG}^{10}$ & & & & & & & & $\mathrm{BCG}^{10}$ & \\
\hline
\end{tabular}

${ }^{1} \mathrm{HepB}=$ hepatitis $\mathrm{B}$ vaccination. The recommended schedule for infants of $\mathrm{HBsAg}(-)$ is shown. However, for infants born to $\mathrm{HBsAg}(+)$ women, passive and active immunoprophylaxis is provided at birth and two additional vaccine doses at the ages of 1-2 months and 6-18 months respectively.

${ }^{2} \mathrm{DTaP}=$ diphteria, tetanus and acellular pertussis vaccine.

${ }^{3} \mathrm{IPV}=$ inactivated polio vaccine.

${ }^{4} \mathrm{Hib}=$ conjugated haemophilus influenzae type $\mathrm{B}$ vaccine

${ }^{5} \mathrm{MCC}=$ meningococcal serotype $\mathrm{C}$ conjugated vaccine.

${ }^{6} \mathrm{PCV}=$ pneumococcal conjugated vaccine.

${ }^{7} \mathrm{MMR}=$ measles, mumps and rubella vaccine.

${ }^{8} \mathrm{HepA}=$ hepatitis $\mathrm{A}$ vaccine.

${ }^{9} \mathrm{~TB}=$ tuberculosis.

${ }^{10} \mathrm{BCG}=$ Bacillus Calmette-Guérin vaccine. Has been recommended to high risk children at birth since 2011.

their children at risk of acquiring a vaccine preventable disease (VPD) [6,7]. Moreover, in close societies where many parents elect to postpone selected vaccines, risk of loss of herd immunity and reemergence of VPDs may occur increasing the chance of outbreaks [6,7]. Additionally, in Greece, recent financial crisis has had a significant impact on access to healthcare services possibly severely affecting vaccination coverage $[8,9]$. Therefore, in order to measure adherence to the NIP an ongoing surveillance system evaluating vaccination coverage, along with other measures including education of the public are necessary. Such systems have been implemented in many countries [10]. We report the results of a prospective survey conducted in 2009-2011, at the beginning of the economic crisis, to assess the vaccination coverage and timely adherence to vaccination scheme among Greek infants aged 2-24 months residing in Metropolitan Athens.

\section{Methods}

\section{Target population}

This study evaluated vaccination coverage rates of infants visiting a tertiary public outpatient care clinic for either acute or routine health visit during 2009-2011. Study was approved form the "P \& A Kyriakou Children's" Hospital Ethics committee. All infants, aged 2-24 months, whose parents and/or legal representative were permanent residents of the greater urban district area of Attica, Greece were informed about the study. Their children were enrolled after informed written consent was provided. Children with underlying chronic disease such as immunodeficiency, extreme prematurity, neurologic diseases or other medical conditions interfering with vaccination administration where excluded. In order to identify predictors of incomplete immunization coverage, parents and/or legal representative of the infant were asked to complete a brief questionnaire to obtain information on demographic and socioeconomic characteristics, health care providers and utilization of immunization health services. The infant was considered as immunized or not based on the immunization card, as provided by the National Greek Health Care System. Parents who did not bring their child's immunization card to the study visits were included in the study and analyzed as a subgroup.

The vaccination coverage for each vaccine was noted. Infants were considered as "adequately immunized" if they had received all vaccines, according to the Greek NIP (Table 1) with $\leq 2$ months delay. To evaluate compliance with the vaccination scheme, 6 month old infants were considered "adequately immunized" if they had received 2 doses of diphtheria, tetanus toxoid and pertussis vaccine (DTP), 2 doses of poliovirus vaccine, 2 doses of Haemophilus influenzae type b vaccine (Hib), 1 dose of conjugated pneumococcal vaccine (PCV) and 1 dose of conjugated vaccine against meningococcus C. Respectively, at the age of 12 months they were considered "adequately immunized" if they had received 3 doses of diphtheria, tetanus toxoid and pertussis vaccine (DTP), 3 doses of poliovirus vaccine, 3 doses of Haemophilus influenzae type b vaccine (Hib), 2 doses of conjugated pneumococcal vaccine $(\mathrm{PCV})$ and 1 dose of 
conjugated vaccine against meningococcus $\mathrm{C}$. The decision for these definitions was based on common practices adopted by Greek pediatricians as discussed below. Moreover, rotavirus vaccination was not included since the vaccine was introduced in the NIP in 2011.

\section{Statistical analysis}

Descriptive statistics are summarized as means \pm standard deviations (SD) for the continuous variables and as frequencies (N) and percentages (\%) for the categorical variables. Univariate logistic analysis was used to assess the association of vaccination coverage with each covariate in isolation.

Multiple logistic regression models are employed with a stepwise variable selection procedure examining those factors found significant during univariate analysis to identify significant variables affecting vaccination coverage. The chosen significant effects were further simplified using multiple comparison methods. All tests were performed at $5 \%$ level of significance. Statistical results were derived using the statistical package $\mathrm{R}$ (version 3.0.2) [http://CRAN.R-project.org/doc].

\section{Results}

\section{Characteristics of study population}

Overall, 1,667 infants were enrolled during the study period with a mean age $13.1 \pm 6.6$ months (51.5\% boys). Enrollment was offered in 1,837 infants (response rate 90.7\%). Main reason given for refusal was lack of time. Demographic and socioeconomic characteristics of the children and their parents as well as patterns of using medical care are shown in Table 2.

Overall, 180 children (10.8\%) were brought without bringing their child's immunization card along. Importantly this group of parents were more likely to have more than 3 children (16.2\%, 95\% CI 11.9\%-20.6\%, p < 0.01), had finished at least high school (for mothers $11.8 \%$, 95\% CI $10.0 \%-13.7 \%, \mathrm{p}<0.01$, for fathers $12.5 \%$, 95\% CI 10.6\%$14.4 \% \mathrm{p}<0.01)$, Greek nationality $(12.7 \%, 95 \% \mathrm{CI}$ $10.4 \%-15.0 \%, \mathrm{p}=0.02)$ and reported visiting the emergency room (ER) for sick visits $(14.1 \%$, 95\% CI 10.8\%$17.4 \%, \mathrm{p}<0.01$ ). Roma children constituted $9.8 \%$ of our population, of which, $63.8 \%$ visited the hospital without their immunization card.

Most parents were able to recall at least one postponement of vaccination (57\%, 95\% CI 54.6\%-59.6\%). Child's suffering from infection was the most frequent reason identified (37.1\%, 95\% CI 34.0\%-40.2\%) while less often parents had forgotten $(9.3 \%, 95 \%$ CI $34.0 \%-40.2 \%)$ or where living too far from a vaccination center $(5.1 \%$, 95\% CI 3.7\%-6.6\%). Finally, 79 parents (4.9\%, 95\% CI $3.9 \%-6.0 \%)$ admitted omitting a vaccine due to their belief that this vaccine was either not necessary or potentially harmful. Parents with no insurance (6.4\%) did not report higher rates of missing vaccination $(57.8 \%, 95 \%$ CI 55.1\%-60.7\%).

\section{Overall vaccination coverage in the study population}

Immunisation coverage for each vaccine is shown in Table 3. Vaccination was confirmed by documentary evidence (immunization card). Coverage was highest for DTP-IPV-Hib. Among the more recently introduced vaccines, children had high vaccination coverage for varicella while coverage for hepatitis A and especially rotavirus vaccine was low (Table 3).

\section{Factors associated with immunization coverage}

Infants were less likely to be fully vaccinated if they belonged to a minority group, had more than one sibling, had young $(<20$ years old $)$ or illiterate parents, had other than public insurance or their parents were unemployed (Table 4). Interestingly, appropriate immunization against hepatitis $B$ ( $\geq 1$ and 3 doses at 6 and 12 months respectively) was strongly associated with the use of the hexavalent vaccine (97.5\% versus $54.2 \%$ and $92.8 \%$ versus $25.7 \%$ respectively, $\mathrm{p}<0.01$, Figure 1 ). Of note, although children belonging to minority groups (immigrants, Roma) were less likely to have received the hexavalent vaccine $(15.6 \%$ versus $32,4 \%, \mathrm{p}<0.01)$, their vaccination coverage rates against hepatitis B were comparable to those of Greek children $(73,2 \%$ versus $80,9 \%, \mathrm{p}=0.16)$.

Multivariate logistic regression analyses were performed to adjust for confounders that may affect the association between risk factors and immunization coverage. After all variables were adjusted, parents' age, occupational and educational statuses were independently associated with immunization coverage at 6 and 12 months (Table 5). Presence of more than 3 children in the family was also found to be an independent predictive factor of the infant's immunisation status.

\section{Discussion}

Vaccination coverage of infants aged 2-24 months old living in metropolitan Athens visiting tertiary public outpatient care clinic for either acute or routine health visit was evaluated. Although vaccination coverage for DTaPIPV-Hib and MMR was high, vaccination against pneumococcal, meningococcal infection and hepatitis B is either delayed or incomplete. Risk factors associated with either incomplete or delayed vaccination were explored.

The selection of the herein criteria used in order to define complete vaccination at 6 and 12 months of age were based on most common practices adopted by Greek pediatricians. In Greece, as in most other Mediterranean countries, children's primary care is anthropocentric and provided by private pediatricians. Overall, parents appear to have a trusting relationship with their private paediatrician [11]. Moreover, during the past few 
Table 2 Demographic and socioeconomic characteristics of the study population

Characteristics
Nationality
Non-minority children
Minority (immigrants, Rom
Place of residence
Inner city Athens
Suburbs
Child's health insurance
Public
Social welfare insurance
Uninsured
Other (private, etc)
Mother's age
$\leq 20$
$21-30$
$31-40$
$\geq 41$

Father's age

$\leq 20$

21-30

$31-40$

$\geq 41$

Mother's education

Illiterate

$<$ high school

High school

$>$ high school

Father's education

Illiterate

$<$ high school

High school

$>$ high school

Mother's occupation

Unemployed

Worker

Public sector employee

Private sector employee

Father's occupation

Unemployed

Worker

Public sector employee

Private sector employee

$\mathbf{N}(\%)$
Total N = 1659
$817(49.25)$
$842(50.75)$

Total $\mathbf{N}=1192$

1068 (89.6)

$124(10.4)$

Total N = 1647

1047 (63.57)

$130(7.89)$

$131(7.95)$

339 (20.58)

Total $\mathbf{N}=1665$

133 (7.99)

$785(47.15)$

$687(41.26)$

60 (3.6)

Total $\mathrm{N}=1649$

$66(4.00)$

457 (27.71)

$845(51.24)$

$281(17.04)$

Total $\mathrm{N}=1648$

159 (9.65)

$281(17.05)$

750 (45.51)

458 (27.79)

Total $\mathrm{N}=1621$

364 (22.46)

$143(8.82)$

$271(16.72)$

$843(52.00)$

Total N $=1664$

1052 (63.22)

$22(1.32)$

$123(7.39)$

467 (28.06)

Total N $=1628$

$268(16.46)$

$348(21.38)$

$166(10.20)$

$846(51.96)$
Table 2 Demographic and socioeconomic characteristics of the study population (Continued)

\begin{tabular}{ll}
\hline Where do you go when your child is sick? & $\begin{array}{l}\text { Total N } \\
=\mathbf{C} 1642\end{array}$ \\
Private Doctor & $983(59.87)$ \\
Hospital emergency room & $433(26.37)$ \\
Social Security outpatient services & $183(11.14)$ \\
Health Center & $43(2.62)$ \\
Regular pediatrician? & Total N = 1657 \\
Yes & $1194(27.77)$ \\
No & $463(71.63)$ \\
Where do you go to get your child vaccinated? & Total N = 1586 \\
Private paediatrician & $866(54.6)$ \\
Social Security outpatient services & $481(30.32)$ \\
Public outpatient clinic & $239(15.07)$ \\
Anthropometric measurements over last & Total N = 1361 \\
$\mathbf{2 4}$ months & \\
0 - 3 times & $236(17.34)$ \\
$>4$ times & $1125(82.66)$
\end{tabular}

Table 3 Immunization coverage in our study population aged 2-24 months

\begin{tabular}{lll}
\hline Vaccine & $\mathrm{n} / \mathrm{N}(\%)$ & $95 \% \mathrm{Cl}$ \\
\hline DTaP-IPV-Hib &
\end{tabular}

$\geq 2$ doses at 6 months

$1.147 / 1.297(88.4 \%) \quad 86.7 \%-90.2 \%$

$\geq 3$ doses at 12 months

$891 / 1.008(88.4 \%) \quad 86.4 \%-90.4 \%$

PCV

$\geq 1$ dose at 6 months

$1.012 / 1.325(77.1 \%) \quad 74.8 \%-79.3 \%$

$\geq 2$ doses at 12 months

$785 / 995(78.9 \%) \quad 76.4 \%-81.4 \%$

MCC

$\geq 1$ dose at 6 months $\quad 518 / 1.279(40.5 \%) \quad 37.8 \%-43.2 \%$

HepB

$\geq 1$ dose at 6 months $\quad 934 / 1.353(69.0 \%) \quad 66.6 \%-71.5 \%$

$\geq 3$ doses at 12 months $\quad 575 / 746(77.1 \%) \quad 74.1 \%-80.1 \%$

MMR*

$287 / 356(80.6 \%) \quad 76.3 \%-84.1 \%$

Varicella*

$308 / 352(87.5 \%) \quad 83.8 \%-91.2 \%$

Rotavirus (2 doses)

$152 / 1.475(10.3 \%) \quad 8.8 \%-11.9 \%$

HAV (one dose at 24 months) $\quad 64 / 151$ (42.4\%) $\quad 34.5 \%-50.3 \%$

*Since according to NIP MMR and varicella should be administered at 12-15 months, children $\geq 17$ months were evaluated.

$\mathrm{DTaP}=$ diphteria, tetanus and acellular pertussis vaccine.

IPV = inactivated polio vaccine.

$\mathrm{Hib}=$ conjugated haemophilus influenzae type $\mathrm{B}$ vaccine.

$M C C=$ meningococcal serotype $C$ conjugated vaccine.

$\mathrm{HepB}=$ hepatitis $\mathrm{B}$ vaccination.

$M M R=$ measles, mumps and rubella vaccine.

$\mathrm{HAV}=$ hepatitis $\mathrm{A}$ vaccine. 
Table 4 Socioeconomic characteristics associated with full immunization

\begin{tabular}{|c|c|c|c|c|c|c|}
\hline \multirow[b]{2}{*}{ Characteristics } & \multicolumn{3}{|l|}{6 months } & \multicolumn{3}{|l|}{12 months } \\
\hline & $\mathrm{n} / \mathrm{N}(\%)$ & RR & $95 \% \mathrm{Cl}$ & $\mathrm{n} / \mathrm{N}(\%)$ & RR & $95 \% \mathrm{Cl}$ \\
\hline \multicolumn{7}{|l|}{ Minority } \\
\hline No & $593 / 627(94.6 \%)$ & & & $481 / 513(93.8 \%)$ & & \\
\hline Yes & $546 / 662(82.5 \%)$ & 0.87 & $0.84-0.91$ & $402 / 487(82.5 \%)$ & 0.88 & $0.84-0.92$ \\
\hline \multicolumn{7}{|l|}{ Family composition } \\
\hline One child & $533 / 589(90.5 \%)$ & & & $436 / 478(91.2 \%)$ & & \\
\hline Two children & 474/532 (89.1\%) & 0.98 & $0.95-1.02$ & $351 / 400(87.8 \%)$ & 0.96 & $0.92-1.01$ \\
\hline More than 3 children & 138/174 (79.3\%) & 0.88 & $0.81-0.95$ & $102 / 128(79.7 \%)$ & 0.87 & $0.80-0.96$ \\
\hline \multicolumn{7}{|l|}{ Child's health insurance } \\
\hline Public & 733/793 (92.4\%) & & & $583 / 645(90.4 \%)$ & & \\
\hline Other & $397 / 486(81.7 \%)$ & 0.88 & $0.84-0.93$ & 295/348 (84.8\%) & 0.94 & 0.89-0.99 \\
\hline \multicolumn{7}{|l|}{ Mother's age } \\
\hline$\leq 20$ & 43/89 (48.3\%) & & & $26 / 54(48.1 \%)$ & & \\
\hline $21-30$ & $552 / 613(90.0 \%)$ & 1.86 & $1.50-2.31$ & 436/495 (88.1\%) & 1.83 & $1.38-2.42$ \\
\hline $31-40$ & $500 / 541(92.4 \%)$ & 1.91 & $1.54-2.37$ & 385 / 415 (92.8\%) & 1.93 & $1.46-2.54$ \\
\hline$\geq 41$ & $50 / 52(96.2 \%)$ & 1.99 & $1.59-2.48$ & 42 / $42(100.0 \%)$ & NA & NA-NA \\
\hline \multicolumn{7}{|l|}{ Father's age } \\
\hline$\leq 20$ & $23 / 46(50.0 \%)$ & & & $11 / 26(42.3 \%)$ & & \\
\hline $21-30$ & $284 / 350(81.1 \%)$ & 1.62 & $1.21-2.18$ & $231 / 279(82.8 \%)$ & 1.96 & $1.25-3.08$ \\
\hline $31-40$ & 626/661 (94.7\%) & 1.89 & $1.42-2.53$ & $472 / 515(91.7 \%)$ & 2.17 & $1.38-3.40$ \\
\hline$\geq 41$ & 205/229 (89.5\%) & 1.79 & $1.34-2.40$ & 170/181 (93.9\%) & 2.22 & $1.41-3.48$ \\
\hline \multicolumn{7}{|l|}{ Mother's education } \\
\hline Illiterate & $57 / 111(51.4 \%)$ & & & 28/71 (39.4\%) & & \\
\hline$<$ high school & 180/225 (80.0\%) & 1.56 & $1.29-1.89$ & $132 / 163(81.0 \%)$ & 2.05 & $1.52-2.77$ \\
\hline High school & $538 / 567(94.9 \%)$ & 1.85 & $1.54-2.22$ & $425 / 450(94.4 \%)$ & 2.39 & $1.79-3.20$ \\
\hline >high school & $355 / 377(94.2 \%)$ & 1.83 & $1.53-2.20$ & 29/307 (94.5\%) & 2.40 & $1.79-3.20$ \\
\hline \multicolumn{7}{|l|}{ Father's education } \\
\hline Illiterate & 49/102 (48.0\%) & & & $29 / 66(43.9 \%)$ & & \\
\hline$<$ high school & 180/219 (82.2\%) & 1.71 & $1.39-2.11$ & 119/154 (77.3\%) & 1.76 & $1.32-2.34$ \\
\hline High school & 609/646 (94.3\%) & 1.96 & $1.60-2.40$ & 499/529 (94.3\%) & 2.15 & $1.63-2.82$ \\
\hline >high school & 276/292 (94.5\%) & 1.97 & $1.60-2.41$ & $214 / 228(93.9 \%)$ & 2.14 & $1.62-2.81$ \\
\hline \multicolumn{7}{|l|}{ Mother's occupation } \\
\hline Unemployed & $422 / 519(81.3 \%)$ & & & $332 / 406(81.8 \%)$ & & \\
\hline Blue collar Worker & 11/15 (73.3\%) & 0.90 & $0.66-1.23$ & $8 / 11(72.7 \%)$ & 0.89 & $0.62-1.28$ \\
\hline Public sector employee & 98/99 (99.0\%) & 1.22 & $1.16-1.27$ & $84 / 84(100.0 \%)$ & NA & NA-NA \\
\hline Private sector employee & 297/311 (95.5\%) & 1.17 & $1.12-1.23$ & $240 / 245(98.0 \%)$ & 1.20 & $1.14-1.26$ \\
\hline \multicolumn{7}{|l|}{ Father's occupation } \\
\hline Unemployed & 167/207 (80.7\%) & & & $118 / 160(73.8 \%)$ & & \\
\hline Worker & 204/266 (76.7\%) & 0.95 & $0.87-1.04$ & 163/201 (81.1\%) & 1.10 & $0.98-1.23$ \\
\hline Public sector employee & $114 / 125(91.2 \%)$ & 1.13 & $1.04-1.23$ & $99 / 99(100.0 \%)$ & NA & NA-NA \\
\hline Private sector employee & $426 / 436(97.7 \%)$ & 1.21 & $1.13-1.30$ & $342 / 359(95.3 \%)$ & 1.29 & $1.17-1.42$ \\
\hline
\end{tabular}




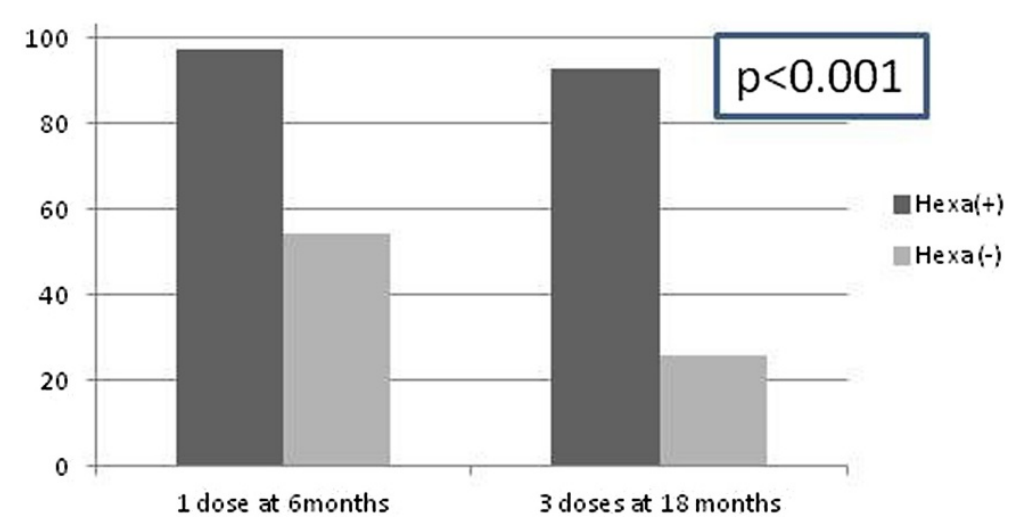

Figure 1 Use of hexavalent vaccine was strongly associated with timely hepatitis B vaccination.

years, since the emergence of economic crisis in Greece, there have been discussions among pediatricians concerning potential need of vaccination priorities reassessment. These refer to vaccinating against pneumococcal disease using the $2+1$ schedule instead of the $3+1$ as currently recommended and postponing meningococcal vaccination for after the first birthday since the incidence of meningococcal $\mathrm{C}$ infection has significantly decreased post universal vaccination implementation. Although these practices have been publicly discussed among experts, there has been no official change in the NIP. Our "acceptance" of these unofficial changes of the NIP may be criticized. This was decided based on observed practices as reported by other studies [2,12-14]. It became evident, that if the analyses were performed with more stringent criteria as advised by the NIP, the reported vaccination coverage would be extremely low impeding the identification of factors associated with incomplete vaccination $[12,13]$.

This may well explain why $40.5 \%$ of 6 month old infants had been vaccinated with one dose of MenC vaccine and $43 \%$ of 12 month old children with three PCV doses. Nevertheless, when compared to the results of the National vaccination study among children born in 2005 results indicate a significant increase in vaccination coverage for MenC (18\% had received two doses at 12 months of age) and PCV (6\% had received 3 doses at 12 months of age), possibly because the children included in our cohort were born at least two years later [2]. Although one can postulate that study population recruited in an outpatient department might have introduced a sample bias, a retrospective study among toddlers attending day care in Athens and Viotia (20102011), reported vaccination coverage with 3 PCV doses during their first year at $46.8 \%$ [13].

In regards to hepatitis $\mathrm{B}, 56.3 \%$ and $77 \%$ of children had received three hepatitis $B$ doses by the age of 12 and 18 months respectively. Importantly, possibly because Greek pediatricians recognize the increased risk of horizontal transmission of hepatitis B, minority children had vaccination coverage rates similar to those of non-minority children, in contrast to our findings on other routine vaccines. Moreover, this occurred despite the significantly reduced use of hexavalent vaccine among minority children. Although all vaccines included in NIP are provided free of charge, the hexavalent vaccine was not included in the repertoire of reimbursed vaccines of a major insurance fund at the time of the study. Thus, infants vaccinated with an hexavalent vaccine might significantly differ from other children in reference to their

Table 5 Multivariate analysis on predictive factors for vaccination coverage

\begin{tabular}{|c|c|c|c|c|}
\hline \multirow[b]{2}{*}{ Risk Factor } & \multicolumn{2}{|c|}{6 months } & \multicolumn{2}{|c|}{12 months } \\
\hline & Adjusted OR (95\% Cl) & $p$ - value & Adjusted OR $(95 \% \mathrm{Cl})$ & $p$ - value \\
\hline$>3$ children & $0.36(0.21-0.63)$ & $<0.001$ & $0.42(0.24-0.72)$ & $<0.001$ \\
\hline Mother's age & NA & NA & $4.71(2.15-10.33)$ & $<0.001$ \\
\hline Father's age & $2.76(1.69-4.5)$ & $<0.001$ & NA & NA \\
\hline Mother unemployed & $0.14(0.03-0.6)$ & $<0.001$ & $3.50(1.35-9.12)$ & $<0.001$ \\
\hline Father working in private sector & $4.48(2.24-8.95)$ & $<0.001$ & $1.7(0.91-3.17)$ & $<0.001$ \\
\hline Mother's education & $3.56(19.5-6.49)$ & $<0.001$ & $1.93(1.18-3.15)$ & $<0.001$ \\
\hline Father's education & NA & NA & $4.19(2.51-7.00)$ & $<0.001$ \\
\hline
\end{tabular}


socioeconomic status, parental attitudes to vaccination. It has been well described that Greek It has been well described that Greek pediatricians often prefer to defer initiation of vaccination against hepatitis $B$ until the second semester of life [12]. In a retrospective study among toddlers attending day care centers in Athens (2010-2011), although 94.3\% were appropriately vaccinated at the age of 4 years, less than a third (27.7\%) had received three hepatitis $B$ vaccine doses during the first year [14]. These results are in accordance with the National vaccination coverage study where although only $36 \%$ of infants had received 3 hepB doses at the age of 12 months, the overall vaccination coverage with 3 doses of hepB among 6 years old children was 98\%. The authors commented that vaccination coverage was lowest in children living in the Athens Metropolitan area [2]. In our study, the median age of receipt of the first hepatitis B vaccine dose was 173 days and only $43 \%$ of infants initiated hepatitis $B$ vaccination before the age of 3 months. Other studies from EU countries also report incomplete vaccination against hepatitis $B$ among their children [15]. Hepatitis B birth dose, which is associated with increased likelihood of early completion of the hepatitis B vaccination is not given in Greece [16]. However, data from Italy where the hexavalent vaccine is used for the vaccination in infants denote significant higher vaccination coverage rates [17]. In concordance to this data, in our cohort, children vaccinated with the hexavalent vaccine were significantly more likely to have received 1 and 3 hepatitis $B$ doses by the age of 6 and 18 months (Figure 1). However, as aforementioned, other confounders such as parental attitudes and economic status may explain the observed difference.

In Greece MMR is administered between 12-15 months of age. In this cohort, $80 \%$ of children over 15 months of age had received MMR vaccination by the age of 17 months (within 2 months from NIP recommendations). Although one may postulate that immunization coverage is lower than expected due to the small number of children $>18$ months included in our cohort (21\%) this is unlikely since $95 \%$ CIs not significantly wider as shown in Table 3. Vaccination coverage was lower than that reported in either the National aforementioned study (91\%) or in the day care center study in Athens $(90.5 \%)[2,14]$. However, in both studies vaccination coverage was estimated at an older age. More importantly these two earlier studies recruited children in schools while our study involved children visiting outpatient clinics. Among the most recently introduced into the NIP programme vaccines (varicella, hepatitis A and rotavirus), varicella vaccination coverage was highest (87.5\%, Table 3). Results were similar to those reported from the National study but significantly higher than those described in the day care center study $(61 \%)[2,14]$. This might be due to the recent introduction of the vaccine in the NIP (2006). However, median age of children attending day care study was 4 years and thus vaccination catch up could have been provided. Vaccination coverage for hepatitis A was lower from the National study where $82 \%$ of the 6 year old schoolchildren had received two doses but this was possibly due to the different age groups in the two cohorts (Table 3). Finally, the low vaccination coverage against rotavirus was expected since although the vaccine is included in the NIP, it is not fully reimbursed and parents still have to pay out of their pockets for $25 \%$ of the vaccine cost (similar for both vaccines available $\sim 28 €$ for complete vaccination). Moreover, this vaccine unlike most other vaccines, is characterized by the NIP-2011 as "recommended" and not as "necessary" which might additionally explain the low vaccination coverage rates observed.

The proportion of parents not bringing their child's immunization card along to the outpatient department was small and this may be due to the common practice of reviewing vaccination history in outpatient visits. Characteristics of those parents are easily explainable since they include highly educated Greek parents, most of which have a private paediatrician, which came in for an emergency visit rather than routine care. Also, in our cohort, 9.7\% of children were Roma and of those only a third brought their vaccination booklet. This is an overrepresentation of this minority population which consists about $1.5 \%$ of Greek population according to data from the Hellenic Ministry of Labour and Social Security. However, in the most recent National vaccination coverage study, researchers included a sub-study of 218 Roma children (median age of 4 years), and found that $87 \%$ owned an immunization card [12].

Univariate analysis indicated that immunization coverage was lowest among infants born to young, illiterate and unemployed parents. Moreover, having more than two siblings or belonging to a minority group was also associated with lower vaccination coverage at 6 or 12 months of age (Table 4). Multivariate analysis (Table 5) confirmed that parent's age, educational and occupational status as well as family size were predictive factors for the infant's immunization status. Interestingly, belonging to a minority group was not associated with incomplete vaccination coverage during multivariate analysis, which could possibly be explained by the composition of the study population where almost $50 \%$ of children were born to immigrants. This might have introduced different confounding factors. As previously suggested, socioeconomic factors such as parental status and family size appear to be the most important predictors associated with under vaccination among Greek children [12]. Interestingly however, in a recent study, higher rather than lower maternal education was associated with incomplete vaccination [14]. Our study confirmed that parental beliefs opposing vaccination 
is not an important factor in Greece today [12]. These findings may be due to the anthropocentric nature of pediatric care in Greece. More importantly, the composition of our population might also justify the absence of anti-vaccine philosophy since our population consisted of urban working class parents with an overrepresentation of working immigrants [18]. In contrary to findings from the National study, in this highly urban population distance to the immunization center or private paediatrician was not perceived as a reason to postpone vaccination [12].

This study was performed at the beginning of the economic crisis in Greece. Only, 6.4\% of parents reported that they had lost their insurance. Notably, rates of missing opportunity to vaccinate were not higher in this group. It will be important to re-examine this growing proportion of our population today since probably under vaccination among these groups may have increased. Although multiple NGOs have organized actions to accommodate preventive measures such as infant vaccination among Greeks that have recently lost their insurance due to unemployment, these actions were not organised centrally at the time. Previous experience in areas undergoing financial crisis indeed has indicated that children are at risk of experiencing negative health-related consequences [8]. Moreover, it becomes evident that austerity measures across Europe have resulted in decreased access to health care and preventive medicine services affecting mainly children and migrants [19-22].

This study has important limitations. Most importantly, it did not include a representative sample but rather a sample of convenience, namely children visiting the outpatient department of an inner city tertiary care children's hospital. It has therefore described the vaccination coverage of children of middle to lower socioeconomic status families residing in Attica with an overrepresentation of minority children and under-representation of higher socioeconomic status families or those residing in rural Greece. However, this cohort of children includes those expected to be mostly affected by the ongoing economic crisis [22]. Therefore identifying gaps and risk factors associated with incomplete vaccination coverage during the early years of economic recession will support focusing future public health interventions aiming to improve immunization delivery in Greece. Another significant limitation involves our selecting less stringent criteria to define complete vaccination at 6 and 12 months of age, based on most common practices adopted by Greek pediatricians. This was however, necessary to make useful analyses. Further discussions with pediatricians on potential need for changes of the NIP due to the crisis is important since primary care is provided through an anthropocentric health care delivery system where vaccinations are mandatory without penalty existing for non-compliance.

\section{Conclusions}

This study indicates that at the beginning of the economic crisis in Greece, incomplete vaccination coverage in toddlers is associated with socioeconomic factors such as parental age, educational and occupational status. Since ongoing recession might further affect vaccination coverage, especially among identified groups, the need for further discussions between primary care pediatricians and public health officials, possibly reassessing vaccination priorities under the current economic situation is apparent.

\section{Abbreviations}

BCG: Bacillus Calmette-Guérin vaccine; DTaP: Diphteria, tetanus and acellular pertussis vaccine; EPI: Expanded Program of Immunization; HAV: Hepatitis A vaccine; HepB: Hepatitis B vaccination; Hib: Conjugated haemophilus influenzae type B vaccine; IPV: Inactivated polio vaccine;

MCC: Meningococcal serotype C conjugated vaccine; MMR: Measles, mumps and rubella vaccine; NIP: National Immunization Programme; OR: Odds ratio; Ref: Reference (value); TB: Tuberculosis; VPD: Vaccine preventable diseases; WHO: World Health Organization.

\section{Competing interests}

VP, MT and DK have received consultations fees but no support for current study. All authors declare they have no competing interests. Supported by a grant from GlaxoSminthKline. There was no influence in study design, interpretation of results or preparing the manuscript.

\section{Authors' contributions}

PV: conceived of the study, participated in its design and coordination and drafted the manuscript. Kl: participated in study design, study coordination and drafting the manuscript. $V A, K E, Z A$ and $A A$ : were responsible for data collection, data entry and statistical analysis of results. TM and KD: participated in the design of the study and critically edited the manuscript. All authors read and approved the final manuscript.

\section{Acknowledgements}

The authors are grateful to all of the study participants and their parents. We would like to thank D. Lambrou for providing assistance in the statistical analysis of our data.

\section{Author details}

${ }^{1}$ Third Pediatric Department, National and Kapodistrian University of Athens Medical School, University General Hospital "ATTIKON", Rimini 1, Chaidari 12462, Greece. ${ }^{2}$ Second Pediatric Department, National and Kapodistrian University of Athens Medical School, "P\&A Kyriakou" Childrens Hospital, Thivon \& Livadias, Goudi 11527, Greece. ${ }^{3}$ Hellenic Health Foundation, Athens, Greece. ${ }^{4}$ First Pediatric Department, National and Kapodistrian University of Athens Medical School, "Agia Sophia" Childrens Hospital, Thivon \& Livadias, Goudi 11527, Greece.

Received: 17 July 2014 Accepted: 10 November 2014 Published: 20 November 2014

\section{References}

1. Hinman AR, Orenstein WA, Schuchat A, Centers for Disease Control and Prevention (CDC): Vaccine-preventable diseases, immunizations, and MMWR-1961-2011. MMWR 2011, 60 Suppl 4:49-57. Surveill Summ.

2. Panagiotopoulos T, Papamichael D, Stavrou D, Laggas D, Gavana M, Salonikioti A, Gogoglou B, Theocharopoulos G, Koutentakis K, Benos A, Giannakopoulos S, Georgakopoulou T, Golfinopoulou K, Detsis M, Keramarou M, Leivaditi B, Mellou K, Danis K, Panteli J, Pervanidou D, Sideroglou T, Tsana M: National Immunization coverage study in Greek children 2012. 2012, http://www.nsph.gr/files/011_Ygeias_Paidiou/Ereunes/ ekthesi_emvolia_2012.pdf (last accessed 30/05/2014).

3. Centers for Disease Control and Prevention (CDC): Vaccination coverage among children in kindergarten-United States, 2012-13 school year. MMWR 2013, 62:607-612. 
4. Blumberg S, Enanoria WT, Lloyd-Smith JO, Lietman TM, Porco TC: Identifying post elimination trends for the introduction and transmissibility of measles in the United States. Am J Epidemiol. 2014, 179:1375-1382.

5. Omer SB, Richards JL, Ward M, Bednarczyk RA: Vaccination policies and rates of exemption from immunization, 2005-2011. N Engl J Med 2012, 367:1170-1171.

6. De Serres G, Gay NJ, Farrington CP: Epidemiology of transmissible disease after elimination. Am J Epidemiol 2000, 151:1039-1048.

7. Omer SB, Salmon DA, Orenstein WA, de Hart MP, Halsey N: Vaccine refusal, mandatory immunization, and the risks of vaccine-preventable diseases. N Engl J Med 2009, 360:1981-1988.

8. Gottret P, Gupta V, Sparkes S, Tandon A, Moran V, Berman P: Protecting pro-poor health services during financial crises: lessons from experience. Adv Health Econ Health Serv Res 2009, 21:23-53. Review.

9. Karanikolos M, Mladovsky P, Cylus J, Thomson S, Basu S, Stuckler D, Mackenbach JP, McKee M: Financial crisis, austerity, and health in Europe. Lancet 2013, 381:1323-1331.

10. Centers for Disease Control and Prevention: National, State, and Local area vaccination coverage among children aged 19-35 Months - United States, 2012. MMWR 2013, 62:733-740.

11. Rousounidis A, Papaevangelou V, Hadjipanayis A, Panagakou S, Theodoridou M, Syrogiannopoulos G, Hadjichristodoulou C: Descriptive study on parents' knowledge, attitudes and practices on antibiotic use and misuse in children with upper respiratory tract infections in Cyprus. Int J Environ Res Public Health 2011, 8:3246-3262.

12. Danis K, Georgakopoulou T, Stavrou T, Laggas D, Panagiotopoulos T: Socioeconomic factors play a more important role in childhood vaccination coverage than parental perceptions: a cross-sectional study in Greece. Vaccine 2010, 28:1861-1869.

13. Grivea IN, Priftis KN, Giotas A, Kotzia D, Tsantouli AG, Douros K, Michoula AN, Syrogiannopoulos GA: Dynamics of pneumococcal carriage among day-care center attendees during the transition from the 7-valent to the higher-valent pneumococcal conjugate vaccines in Greece. Vaccine 2014, [epub ahead of print].

14. Pavlopoulou ID, Michail KA, Samoli E, Tsiftis G, Tsoumakas K: Immunization coverage and predictive factors for complete and age-appropriate vaccination among preschoolers in Athens, Greece: a cross-sectional study. BMC Public Health 2013, 13:908.

15. Fonteneau L, Urcun JM, Guthmann JP, Collet M, Neulat N, Bristol-Gauzy P, Guignon N, Lévy-Bruhl D, Herbet JB: Vaccination coverage in 6-year-old preschool children, France, 2005-2006. Arch Pediatr 2013, 20:241-247.

16. Yusuf HR, Daniels D, Smith P, Coronado V, Rodewald L: Association between administration of hepatitis $B$ vaccine at birth and completion of the hepatitis $B$ and 4:3:1:3 vaccine series. JAMA 2000, 284:978-983.

17. Baldo V, Bonanni P, Castro M, Gabutti G, Franco E, Marchetti F, Prato R, Vitale F: Combined hexavalent diphtheria-tetanus-acellular pertussis-hepatitis B-inactivated poliovirus-Hemophilus influenzae type $b$ vaccine; Infanrix ${ }^{\mathrm{TM}}$ hexa: Twelve years of experience in Italy. Hum Vaccin Immunother 2014 10:129-137.

18. Prislin R, Dyer JA, Blakely $C H$, Johnson CD: Immunization status and sociodemographic characteristics: the mediating role of beliefs, attitudes, and perceived control. Am J Public Health 1988, 88:1821-1826.

19. Kentikelenis A, Karanikolos M, Papanicolas I, Basu S, McKee M, Stuckler D: Health effects of financial crisis: omens of a Greek tragedy. Lancet 2011, 378:1457-1458.

20. McKee M, Karanikolos M, Belcher P, Stuckler D: Austerity: a failed experiment on the people of Europe. Clin Med 2012, 12:346-350

21. Rechel B, Mladovsky P, Ingleby D, Mackenbach JP, McKee M: Migration and health in an increasingly diverse Europe. Lancet 2013, 381:1235-1245.

22. Wolfe I, Thompson M, Gill P, Tamburlini G, Blair M, van den Bruel A, Ehrich J, Pettoello-Mantovani M, Janson S, Karanikolos M, McKee M: Health services for children in Western Europe. Lancet 2013, 381:1224-1234.

doi:10.1186/1471-2458-14-1192

Cite this article as: Vassiliki et al: Determinants of vaccination coverage and adherence to the Greek national immunization program among infants aged 2-24 months at the beginning of the economic crisis (2009-2011). BMC Public Health 2014 14:1192.

\section{Submit your next manuscript to BioMed Central and take full advantage of:}

- Convenient online submission

- Thorough peer review

- No space constraints or color figure charges

- Immediate publication on acceptance

- Inclusion in PubMed, CAS, Scopus and Google Scholar

- Research which is freely available for redistribution 